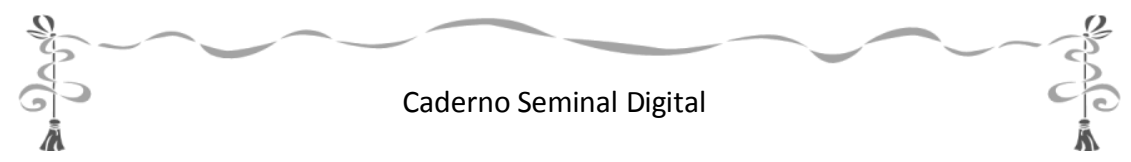

\title{
A BAHIA DE JORGE AMADO E AS DOS TRADUTORES LITERÁRIOS: ENCONTROS E DESENCONTROS.
}

JORGE AMADO'S BAHIA AND THAT OF THE LITERARY TRANSLATORS: ENCOUNTERS AND MISENCOUNTERS

André Luiz Ming Garcia (USP/CAPES) Érica Santos Soares de Freitas (USP/CAPES)

Resumo: O objetivo deste trabalho é, com base em uma análise das traduções ao espanhol peninsular e ao catalão de Gabriela, cravo e canela (Amado), discutir o papel do tradutor literário e sua responsabilidade social. O tradutor desempenha o papel de um mediador cultural (KATAN, 1996) e realizador do que chamamos de vórtex intercultural, i.e. , uma janela aberta pela tradução que estabelece uma ponte de observação de aspectos da cultura do "outro". Observar-se-ão, pelas análises feitas, as escolhas dos tradutores, diante das dificuldades geradas pela intensa presença de culturemas (VEERMER, apud MARTÍNEZ, 2001) no texto origem, pois corresponderam a diferentes normas e, em uma variedade de casos, contribuíram com a manutenção e a expansão de preconceitos acerca de aspectos da cultura baiana (e brasileira), pouco conhecidos na Espanha.

Palavras-chave: Tradutologia; Estudos Interculturais; Gabriela, cravo e canela; mediação intercultural; alteridade.

Abstract: The aim of this work is, based on an analysis of the translations into Spanish and Catalan of Gabriela, Clove and Cinnamon (Amado), to discuss the role of the literary translator and his social responsibility. The translator plays the role of a cultural mediator (KATAN, 1996) and director of what we call intercultural

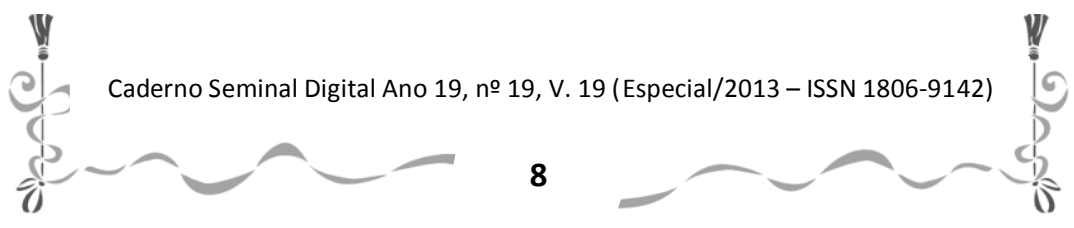


vortex, i.e., an open window for the translation establishing a bridge for observation of aspects of the culture of "the other." It shall be observed, by the analyzes made, that the choices of the translators, given the difficulties caused by the intense presence of intense culturemes (VERMEER, apud MARTíNEZ, 2001) in the source text correspond to different standards, and in a variety of cases, contributed with the maintenance and expansion of prejudices about aspects of the culture of Bahia (and Brazil), which are little known in Spain.

Keywords: Cultural studies; Literary translation; Gabriela, cravo e canela; intercultural mediation; alterity.

\section{INTRODUÇÃO}

O presente trabalho insere-se no âmbito da tradutologia, especificamente nos estudos acerca da tradução literária e dos estudos interculturais. Seu objetivo geral é abordar as relações entre as escolhas do tradutor, a fim de que este resolva conflitos relativos à tradução de referentes culturais e à representação geral da cultura traduzida no seio da cultura do texto-meta.

Neste caso, dedicar-nos-emos, especificamente, a algumas traduções espanholas ao castelhano e ao catalão, de Gabriela, cravo e canela (Gabriela, clavo y canela, e Gabriela, clau y canyella, respectivamente), de Jorge Amado, com vista a analisarmos a resolução de dificuldades oriundas na tradução de referentes culturais pertencentes à gastronomia locais existentes nesse texto. Observaremos, ainda, as

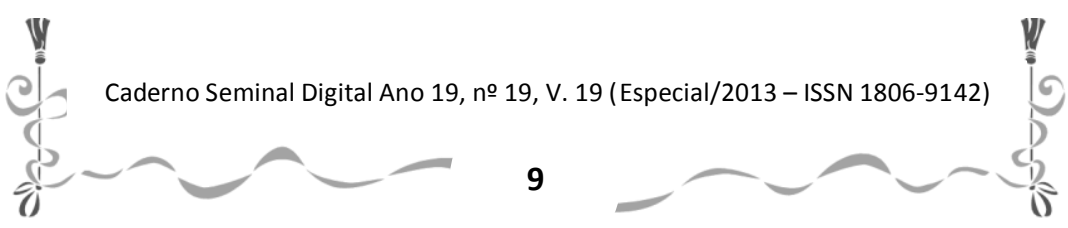


pronunciadas diferenças entre esses referentes e a cultura europeia, em geral, que tornam seu processo de tradução uma tarefa bastante árdua.

Com base em conceitos advindos da semiótica, partimos do pressuposto de que a tradução consiste de uma aproximação quase paralela de uma expansão semiótica de duas culturas diferentes; porém, ao se tratar de um novo texto estruturado em outra língua, embora com uma subversão da função semiótica tradicional dos signos que o compões, permite uma breve proximidade à cultura do "outro", e se oferece como uma janela através da qual se pode espreitar elementos da outra cultura, janela que chamaremos "vórtex intercultural". O número e os tipos de camadas interpoladas entre o vórtex e o objeto intercultural determinarão o valor e a forma de representação recebida pela cultura traduzida na língua e cultura-meta.

Nossa proposta não consiste em realizar, ao longo deste texto, uma análise exaustiva de todas as ocorrências dos referentes existentes, pois não é o escopo deste trabalho. Nossa intenção é observar alguns exemplos considerados mais significativos, cuja verificação possibilitará o cumprimento de nossos objetivos. Pretendemos chamar a atenção do leitor para a relação de reiteração de preconceitos populares e préexistentes em uma cultura, por meio da tradução irradiante de tais preconceitos. Demonstraremos que, ao mesmo tempo em que a obra literária (e sua tradução) pode refletir a imagem

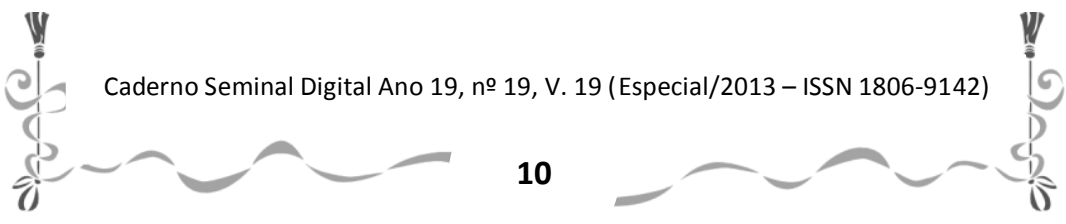


Caderno Seminal Digital

Â.

que dentro de uma cultura faz-se da "outra", funciona, ademais, como fonte de informação ou desinformação e resolução ou estabelecimento de estereótipos relacionados com essa outra cultura. No caso da brasileira (mais especificamente da baiana), retratada nos textos de Jorge Amado, tal análise demonstra-se muito relevante, ao se tratar de uma cultura sul-americana, sobre a qual chegam à Europa informações por vezes parciais, destorcidas e impregnadas de fortes estereótipos (MENDES, 2004).

Ao mesmo tempo em que debateremos o papel do mediador cultural e sua responsabilidade social, que em determinadas traduções circulantes da Espanha das obras mencionadas, não apenas prejudicam e diminuem o nível geral de informação acerca das culturas brasileira e sulamericanas, mas também reforçam preconceitos e deturpações de manifestações culturais desse subcontinente.

Na primeira parte, exporemos os fundamentos teóricos que nos permitiram proceder, na segunda parte, à análise crítica das traduções dos textos analisados e do conteúdo ideológico implícito de determinadas escolhas dos tradutores. Para tal, utilizaremos um corpus de culturemas recortados das traduções, a fim de compará-lo com o texto original de Amado. Ao final, apresentaremos nossas considerações e sugestões.

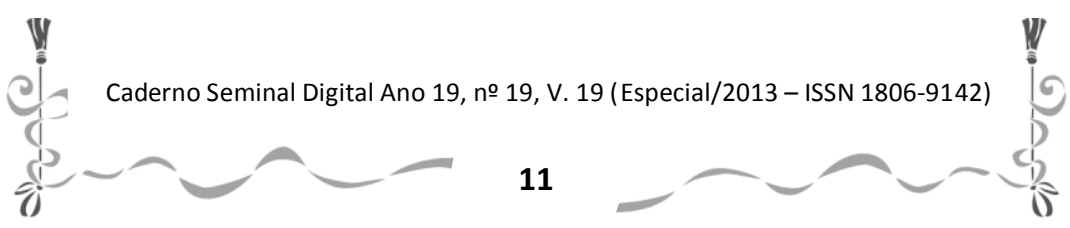


Caderno Seminal Digital

\section{FUNDAMENTAÇÃO TEÓRICA}

Quero falar da descoberta que o eu faz do outro. $O$ assunto é imenso.

Tzvetan Todorov

Toda área de conhecimento consiste, a priori, numa área de desconhecimento; o paradoxo é explicado se distinguirmos as pessoas não especializadas das especialistas no assunto. Em relação aos estudos linguísticos, tradutológicos e interculturais, a mesma contradição surge bastante pronunciada, visto que o falante é habilitado a falar sua língua materna e, por meio dela, manipula a linguagem; caso esteja capacitado a falar duas ou mais línguas, além da linguagem observará distinções entre culturas, visto que domina os atos de traduzir e decodificar.

Para muitos, a linguagem em si, a atividade tradutora ou as relações transculturais são realidades quase indiscutíveis, das quais todos somos mestres, contudo podemos nos deter, de momento, às considerações de Carbonell (1997), a respeito do fenômeno tradutológico:

Tradicionalmente se ha considerado la traducción como una actividad mimética. Aunque la traducción lingüística, relacionada con la cuestión tan trillada de la equivalencia, parece aspirar a una redefinición del significado de un texto en el otro, a la reconstrucción de un contexto lingüístico y semántico equivalente, de hecho aquella trasciende la circularidad cerrada de la mera imitación

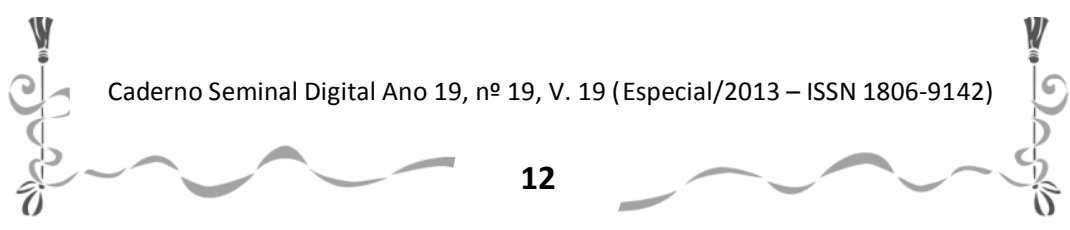




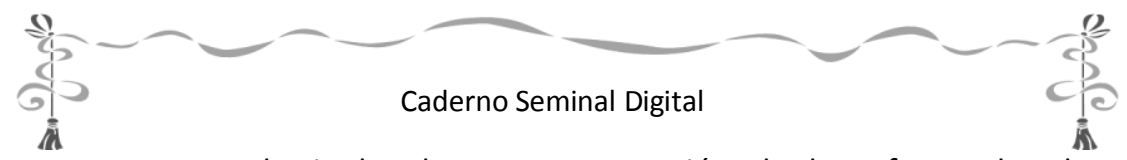

hacia la abertura y expansión de la esfera cultural. (Carbonell, Ibídem, p.147)

O reconhecimento da atividade tradutora como "puente creado desde nuestra propia cultura y con nuestros propios materiales [que] comparte las mismas estrategias de representación con las que se pinta la "otra cultura'" (CARBONELL, Ibidem) passou a ser, desde o último século, o enfoque principal, segundo o qual se analisa a tradução, e cada vez mais se lhe confere um papel destacado nos estudos interculturais e xenológicos.

A tradução é, portanto, uma troca de informações e de manifestações culturais e linguísticas entre diferentes comunidades, que promove o enriquecimento e ampliação do horizonte cultural de ambas, devido a expor elementos de uma determinada cultura aos membros de outra. Para que isso ocorra, sempre há necessidade de adaptação dos referentes culturais que a obra original contenha, a fim de que - tradutor possa realizar a transposição desses referentes. Entretanto, há também implicações ideológicas das decisões que acompanham esse processo e o tradutor será o responsável pela cultura com que se deparará ao ler o texto em sua língua. Dessa forma, é grande a responsabilidade desse profissional, dada sua prática envolver a valorização da cultura e de aspectos seus aos olhos dos membros de outra comunidade.

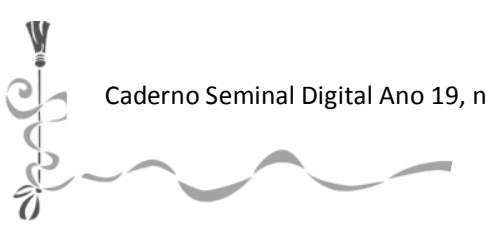

13

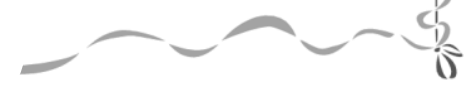


De acordo com Saussure (2000), os signos regem-se pelo princípio da linearidade: o encadeamento linear e sintagmático permite a construção de frases e textos. Peirce (1931-1935) também aponta esse princípio, definindo o homem como um signo; a vida, uma sucessão de signos; e a semiose, ou ação dos signos, é o funcionamento gerador de significados.

Cada sistema linguístico é um conjunto de signos ativos em constante expansão, que se desenvolvem, encadeiam-se e implicam de acordo com as condições próprias daquele sistema e da cultura que reflete e na qual se desenvolve; entretanto, os intercâmbios de informação intrínsecos à práxis tradutora põem dois sistemas linguístico-culturais em contato e, salvaguardadas suas diferenças, permitem que se relacionem, enriqueçam-se e, em dados momentos, expandam-se por caminhos "quase" paralelos.

Carbonell (Ibidem) indica que tradicionalmente a tradução é considerada uma atividade mimética; contudo, parece-nos que essa ação é muito mais que isso, pois aspira a una redefinição de significado de um texto no outro, a uma reconstrução de um contexto linguístico y semântico equivalente.

Os conceitos desenvolvidos por Gamader e Jausch no centro dos estudos da recepção de textos literários e adaptados ao contexto dos estudos interculturais por Golden

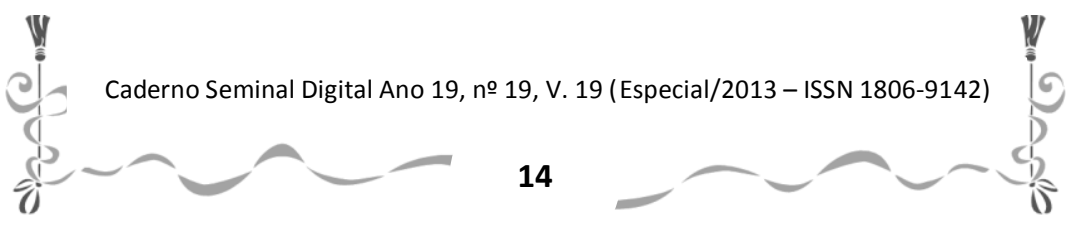


Caderno Seminal Digital

至

(2003), para mais adiante relacioná-los à temática da tradução. Os teóricos alemães

proposen el concepte d'un horitzó cultural que és comú a totes les persones que formen part del mateix grup sociocultural al mateix lloc en el mateix moment històric. Totes aquestes persones comparteixen referències del món material i del món sociocultural. Perquè comparteixen les mateixes referències, participen en la intertextualitat dels textos o de les altres manifestacions culturals (...) i en la intersubjectivitat de la comprensió dels textos o de les altres manifestacions culturals. (...) El concepte de la intersubjectivitat suggereix que hi ha moltes referències culturals que tothom del mateix grup sociocultural comparteix. (...) Què passa quan aquesta persona vol comprendre una cultura diferent? (...) Ha d'acostar-se a l'altre món. (...) És un procés diferent, (...) un procés conscient. (...). Aquest procés canvia la persona que l'empren. Deixa de ser una persona tancada dins I'horitzó i dins el cercle hermenèutic de la seva pròpia cultura i, sense convertir-se del tot en persona totalmente asimilada a l'altra cultura, comença a habitar un nou espai entre les dues cultures en contacte (Ibidem, p. 5-6).

Não são poucas as questões que suscitam as aplicações desses conceitos no campo da tradução. O tradutor, em teoria, é uma pessoa que atravessou um processo de "hibridização" cultural, de abertura direcionada a um novo círculo hermenêutico, que habitam um espaço de intersecção entre duas oi mais esferas culturais.

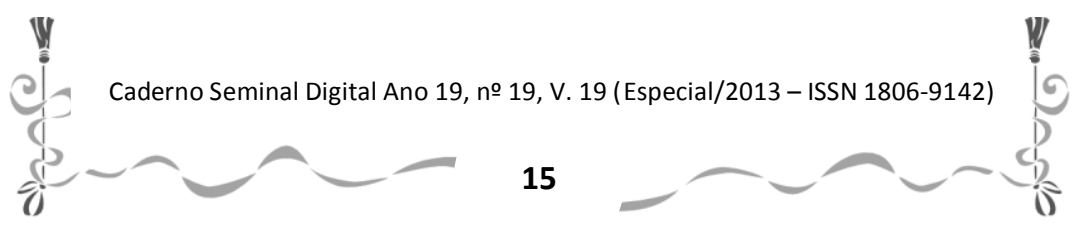


Caderno Seminal Digital

E os leitores de um texto traduzido? Trata-se, na maior parte, de pessoas que dependem da ajuda do tradutor para que lhes construa uma janela a fim de lhes permitir visualizarem manifestações culturais de outra comunidade linguística, de outra realidade cultural, com suas tradições, costumes, valores, história, dinâmicas sociais e, por que não, ideologias, aqui compreendidas como valores, conceitos, crenças e condicionamentos culturais compartilhados por determinados grupos. Por esse motivo, podemos afirmar que o tradutor detém grande responsabilidade, por representar aos membros de sua cultura elementos da cultura alheia, muitas vezes desconhecidos e, indubitavelmente, diversos dos seus.

Os estudos da tradução dos elementos culturais tomaram força a partir das contribuições de Nida (1945), que estabelece uma divisão de âmbitos culturais, a fim de classificar tais elementos, a saber: a) o âmbito ecológico, b) a cultura material; c) a cultura social; d) a cultura religiosa; e) a cultura linguística (especificidades fonológicas, morfológicas, sintáticas e léxicas de cada língua). Newmark (1988) adaptou a proposta de Nida e apresenta as categorias de classificação do que denomina "palavras culturais estrangeiras" como sendo: a) ecologia; b) cultura material (produtos e objetos); c) cultura social (trabalho e lazer); d) costumes, ideias e organização; e) hábitos e gestos.

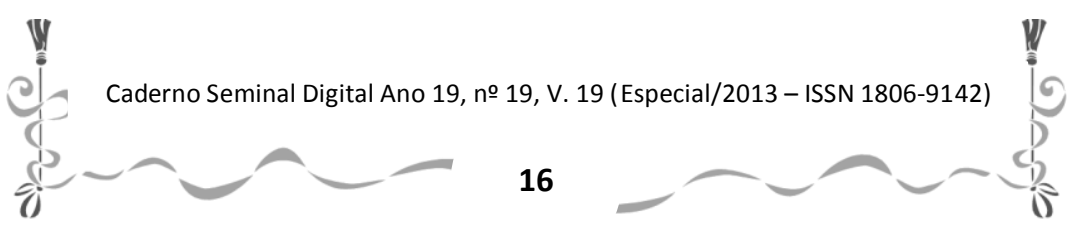


Por sua vez, Vlakhov y Florin (1979, apud MARTíNEZ, 2001), introduzem o termo "realia" para se referirem a elementos textuais que marcam referências à cultura e às histórias locais, subdividindo-as nas categorias: a) geográficos e etnográficos; b) mitológicos e folclóricos; c) objetos cotidianos; d) sociais e históricos. Vermeer recupera o conceito de culturema previamente criado por Oksaar (cf. Martínez, Ibidem), que define como "un fenómeno social de la cultura $x$ que es entendido como relevante por los miembros de esa cultura, y que comparado con un fenómeno correspondiente de la cultura y, resulta ser percibido como especifico de la cultura $x^{\prime \prime}$ (Ibidem).

Consideramos os elementos culturais (culturemas) como chave de recriação de um texto em outra língua e cultura, e origem da maior parte das dificuldades enfrentadas por um tradutor no momento de compor esse novo texto. São múltiplas as possibilidades de adaptação, tradução e equivalência desses elementos no seio de uma cultura, e a existência de diferentes traduções do mesmo texto a uma mesma língua estrangeira, as quais apontam o papel desempenhado pelas escolhas do tradutor no momento de proceder a essa representação cultural e de seus elementos e manifestações próprios dos membros de outra. Essas escolhas também se determinam pela ética (ou falta de), pelos posicionamentos políticos e pelas impressões pessoais acerca de ambas as culturas.

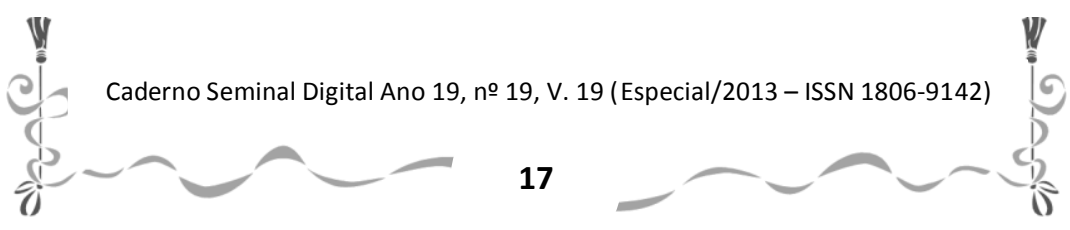


Caderno Seminal Digital

\section{OS PERFIS DA BAHIA ELEITA}

De acordo com Martínez (2001, p. 3), “las obras literarias son un parámetro indicativo de la imagen que la cultura receptora tiene de la cultura a la que pertenece el texto original". Para ela, a metodologia empregada pelo tradutor, muitas vezes pretende desenvolver

una equivalencia formal, una equivalencia orientada a los receptores meta, una versión exotizante...) seguido en la traducción se adopta dependiendo de un entramado de circunstancias y propósitos que rodean al texto (la modalidad de la traducción, la finalidad de la traducción, las características del receptor meta, etc.), y es uno de los filtros mediante los que se genera la proyección de esa imagen. (Ibidem)

No caso de se propor a reescrever textos literários brasileiros em línguas espanholas neolatinas, como o castelhano e o catalão, o tradutor assume uma notável responsabilidade, visto que se aventura na reconstrução de uma realidade sociocultural e histórica, paradoxalmente próxima e afastada da de seu leitor, em textos em que abundam referentes e/ou elementos culturais sustentados por um sistema diverso de crenças, organização social, situação geográfica, costumes etc.

Mendes (2004), com base em sua experiência como docente de língua portuguesa, cultura brasileira e tradução na Universidad Autónoma de Barcelona, pondera que

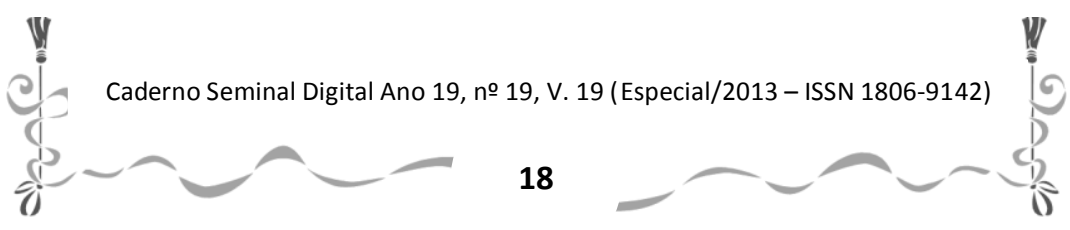




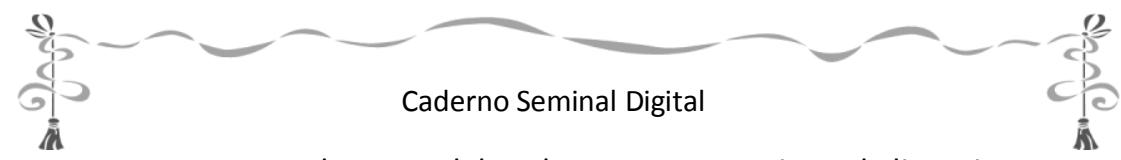

por lo general, los alumnos que empiezan la licenciatura y que optan por el portugués como segunda lengua extranjera suelen tener un conocimiento muy escaso y muchas veces tienen muchos estereotipos de los países de lengua oficial portuguesa. Sobre Brasil tienen la imagen típica de "país de fútbol, carnaval y violencia" que se transmite en Europa por los medios de comunicación de masas, (...) es de gran importancia sensibilizar al alumno para que pueda adquirir una visión más completa y realista de la cultura brasileña así como capacitarlo para que entienda, asimile e interiorice la lengua portuguesa dentro de un contexto cultural, adquiriendo los conocimientos básicos imprescindibles para la actividad del traductor del portugués en distintos tipos de textos. (Ibidem)

Percebemos, nesses comentários, que o desconhecimento ou a desinformação sobre a cultura brasileira afeta também pessoas interessadas nela, como os alunos universitários de língua portuguesa e cultura brasileira apontados pela professora. Pode-se supor, portanto, sem equívocos, que um leitor estrangeiro em potencial de uma obra de literatura brasileira, de estilo regionalista e impregnada de referências culturais, como as de Jorge Amado, é inicialmente um interessado nessa cultura, alguém que decidiu se aventurar na descoberta do outro para experimentar as fases de experiência com alteridade.

Ao recompor um texto de Jorge Amado, o tradutor vêse diante de inúmeras dificuldades, por encontrar em suas obras uma imensa proliferação de referências culturais próprias do Nordeste brasileiro (e, mais especificamente, do estado da Bahia), em grande parte desconhecidas do próprio

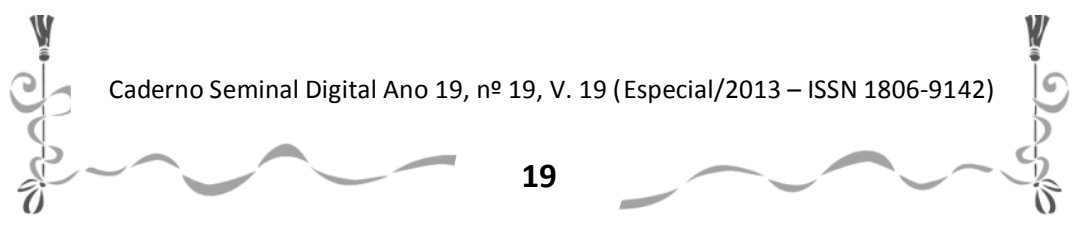


Caderno Seminal Digital

空

público brasileiro oriundo de outras regiões e totalmente alheias à cultura europeia, em geral.

O escopo de nosso trabalho, portanto, corresponde a uma análise de dois tipos de elementos culturais geradores de uma considerável dificuldade ao seu tradutor: referências à gastronomia. Essa escolha deve-se ao fato de que as formas de manifestação da religiosidade na Bahia caracterizam-se por um composto heteróclito de empréstimos de símbolos advindos, principalmente, da cultura africana. No caso da culinária típica da região (muitas vezes considerada exótica), há muitos empréstimos africanos, ingredientes regionais e preparos distintos, diversos deles possuindo um étimo cultural relacionado, ao mesmo tempo, a dois universos culturais (brasileiro e africanos), com alguns pratos eleitos para serem ofertados a divindades. Dessa forma, a arte e a técnica de cozinhar pode ser bastante estereotipada, simplificada e negligenciada, com equívocos que remetem o leitor a imagens completamente distorcidas.

Vejamos alguns itens analisados nas obras em questão, indicadas a seguir:

Obra A: Castelhano - Amado, Jorge. Gabriela, clavo y canela. Trad. Haudée Jofré Barroso. Barcelona: Seix Barral, 1985. (Gabriela, clavo y canela. Trad. Hayde Joffre Barroso. Madrid: Unidade Editorial, 1999).

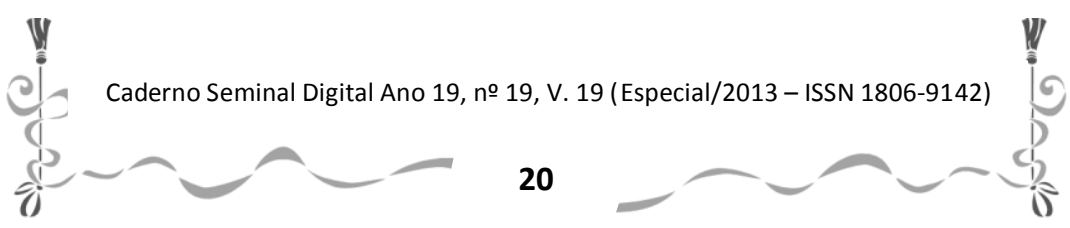


Caderno Seminal Digital

Obra B: Castelhano - Amado, Jorge. Gabriela, clavo y canela: crónica de una ciudad de interior. Trad. Dante Hermo. Barcelona: El Aleph, 2002.

Obra C: Catalão - Amado, Jorge. Gabriela, clau i canyella: Crònica d'Una Ciutat de I'Interior. Trad. Anna Alsina Keith. Barcelona: Edicions 62, 1997.

\subsection{Culturemas analisados}

Com referência ao âmbito gastronômico, ao se traduzirem os nomes dos pratos mingau, cuscuz e bolos de tapioca, os resultados observados foram, respectivamente:

OBRA A: (AMADO, 1985, p. 40): são mantidas as formas mingau y cuscuz entre aspas. O terceiro prato foi traduzido como bolinhos de tapioca. Para mingau, o tradutor não ofereceu nenhuma explicação, mas poderia ter indicado, ainda que em nota de rodapé, o equivalente espanhol papilla, que funcionaria com muita precisão nesse caso. Em nota de rodapé, explicou a natureza do cuscuz baiano, a fim de diferenciá-lo do marroquino (conhecido na Espanha). Observamos uma provável adaptação indevida no caso do bolinho de tapioca, visto que o equivalente espanhol de bolo é, de fato, bizcocho ou pastel.

OBRA B: Na outra tradução (Amado, 2002, p. 31), os bolos de tapioca surgem como tortas de tapioca, ou seja, bastante impreciso. $O$ termo cuscuz não está traduzido e nem

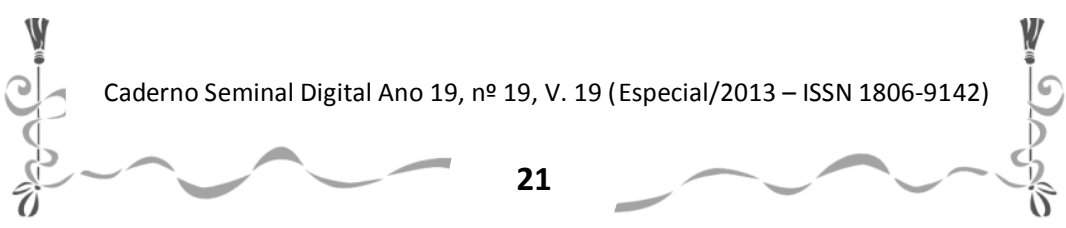


Caderno Seminal Digital

A

possui explicação, o que provoca, com certeza, associação totalmente equivocada com o cous-cous marroquino. Em relação ao mingau, o tradutor optou manter a palavra e incluir uma nota explicativa do significado, que coincide com o equivalente espanhol papilla.

OBRA C: Na tradução catalã (Amado 1997, p. 34) o mingau está traduzido como farineta, forma equivalente e apropriada para representar o prato. Entretanto, o tradutor optou por manter a forma idêntica para cuscuz, o que pode gerar, como na Obra B, equívoco com o prato. Ainda, surgem as boletes de tapioca, o que nos faz pensar quão confuso pode ser, imageticamente, para o leitor, visto que "bolinhas" podem se referir a qualquer tipo de bola; se o leitor não sabe que tapioca é uma comida, provavelmente nem imaginará a possibilidade de esse sintagma aludir a um prato típico brasileiro.

Para os termos acarajés, abarás, bolinhos de mandioca e puba, e frigideiras de siri mole, a confusão tradutológica foi maior, devido a serem pratos tipicamente brasileiros, específicos da Bahia, com referências, inclusive, a espécies de vegetal e animal não existentes na Europa.

OBRA A: En Amado (1985, p. 49-50), o tradutor optou por manter entre aspas as expressões brasileiras e incluir um glossário para definir esses referentes culturais. A definição de acarajé como "papilla de poroto cocinado, frita en aceite de 'dendê'", é imprecisa, visto que se trata de um tipo de

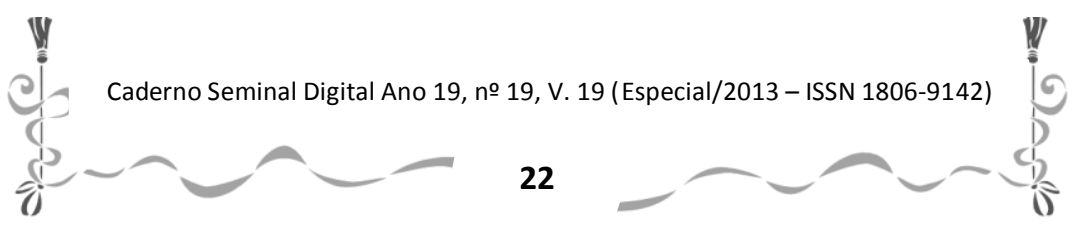


Caderno Seminal Digital

î.

croquete (croqueta) ou bolinho frito (bollitos) e não uma papilla (mingau). Além disso, introduz outra dúvida ao leitor, ao se referir ao azeite de dendê sem explicar que se trata de um óleo extraído de uma espécie de palmeira.

A definição de abará está como "plato muy similar al 'acarajé', solamente que la masa está adobada con pimienta y condimentos" está equivocada, pois a distinção entre abará e acarajé é por este ser frito e apimentado e aquele, cozido e sem pimenta. Segundo Houaiss (2001), abará é uma "porção de feijão-fradinho descascado e moído, temperada com sal, cebola, azeite de dendê e camarão seco, e cozida em banhomaria ou vapor, depois de enrolada em folha verde de bananeira" e acarajé é um "bolinho de feijão-fradinho descascado, moído, temperado com sal e cebola ralada, muito bem batido antes de ser frito no azeite de dendê, e servido com molho de pimenta-malagueta, camarões secos, vatapá, tomate e pimentão".

Para os termos bolinhos de mandioca e puba: não há explicação. A definição de siri é altamente enganosa: "nombre común a varias especies de crustáceos", visto que este animal é de uma espécie muito definida e específica de crustáceo. Poderia ter sido comparado a um pequeno caranguejo; uma aproximação não tão precisa, porém mais esclarecedora. Faltou, ainda, indicar a curiosidade do prato, frito e feito com o siri jovem.

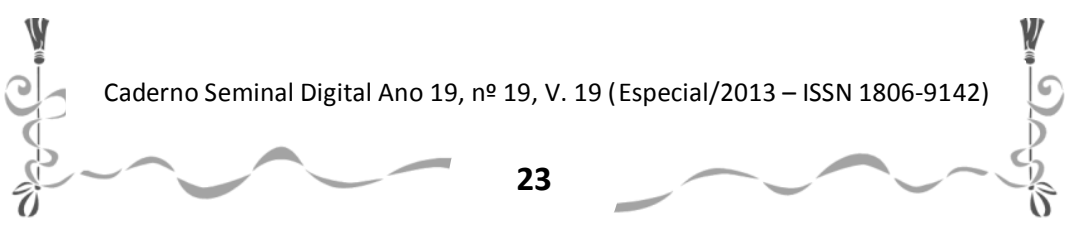


Caderno Seminal Digital

OBRA B: Em Amado (2002, p. 62), o tradutor solucionou sua tradução do mesmo modo que o da obra $A$, mantendo as palavras brasileiras intocadas, sublinhadas, incluindo explicações posteriores, as quais, nesse caso, aproximam-se ao significado dos nomes dos pratos.

OBRA C: Na versão catalã (Amado 1997, p. 66), o tradutor optou por manter em português e sublinhados os referentes acarajés e abarás. As explicações estão um pouco confusas e distorcidas, mas incluem um dado cultural: a origem dos pratos:

a) acarajés: fulles de plàtan farcides amb pasta de mongetes. Duu moltes espècies picants. Plat de la cuïna afrobrasilera (folhas de bananeira recheadas com pasta de feijão. Contém um monte de especiarias picantes. Prato da culinária Afro-brasileira1). A imagem projetada em sua explicação remete a algo completamente diferente de um bolinho frito; em seu desdobramento, indica que o acarajé, inclusive, é uma comida envolta por uma folha de bananeira.

b) abarás: boletes de pasta de mongeta fregides en oli de palmera. Plat típic de la cuina afrobrasilera (bolinhos de pasta de feijão, fritas em óleo de palmeira. Prato típico da cozinha afro-brasileira2). Ainda que o tradutor tenha tentado

1 Tradução nossa.

2 Tradução nossa.

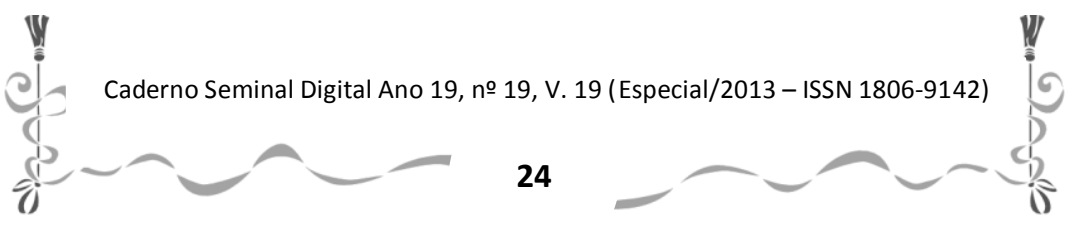


Caderno Seminal Digital

Â

buscar a origem dos pratos, equivocou-se ao informar que o abará é frito.

Para as expressões bolinhos de mandioca e puba, frigideiras de siri mole, o tradutor tentou buscar equivalentes no catalão, porém sem sucesso: respectivamente, boletes de mandioca fermentada e peixets fregits.

Os exemplos mostram que, não obstante as exceções, faltou a esses tradutores um maior rigor durante a investigação dos significados reais dos referentes. Em muitos casos, não se trata de termos conhecidos nas culturas espanhola e catalã; por esta razão, deveriam estar explicados por meio de uma pesquisa feita sobre a cultura brasileira, precisamente a da culinária baiana. A maior parte dos dados consta em dicionários monolíngues de português; a internet permite localizar com grande facilidade, hoje em dia, páginas confiáveis sobre culinária e cultura gastronômica, inclusive com imagens dos pratos mencionados, importantes para a compreensão do contexto da obra analisada.

\section{CONSIDERAÇÕES FINAIS}

Em grande parte dos exemplos, sobretudo na tradução castelhana de 1985/1999, as explicações não oferecem ao leitor informações precisas acerca dos referentes culturais e, em alguns casos, conduzem a ideias completamente equivocadas.

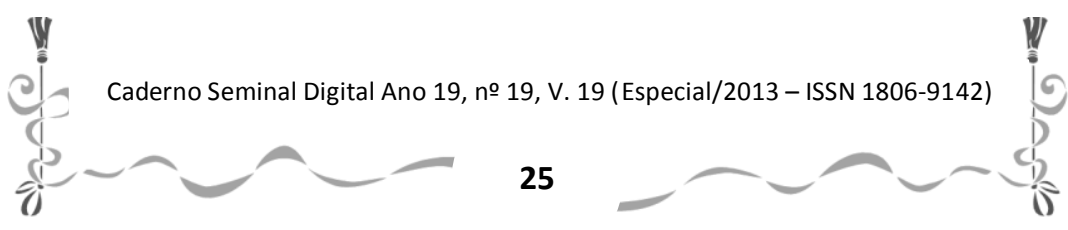


A tradução pode ser, como visto, um grande problema que acarreta mal-entendidos e descaracterização do aspecto cultural de qualquer comunidade. Desse modo, percebemos a falta de critérios adequados para que a obra fosse traduzida com propriedade, a fim de transpor para aquelas línguas todo o ambiente cultural em que se insere.

Cabe ao tradutor, portanto, atuar como ponte de comunicação entre diferentes culturas ao disseminar conhecimento real, sem reforçar prejuízos e dificuldades de convivência geradas por deturpações nos conceitos de identidade, autoimagem e imagem dentro do outro (KRISTEVA, 1994).

Há, ainda, marcas ideológicas implícitas que apresentam explicações e falsos equivalentes, carregados de prejuízos e influenciados por uma visão estereotipada da culinária afro-brasileira.

\section{REFERÊNCIAS BIBLIOGRÁFICAS}

Amado, J. (1985). Gabriela, clavo y canela. Trad. Haudée Jofré Barroso. Barcelona: Seix Barral.

. (1997). Gabriela, clau i canyella. Trad. Anna Alsina Keith. Barcelona: Edicions 62.

. (1999). Gabriela, clavo y canela. Trad. Hayde Joffre Barroso. Madrid: Unidade Editorial. . (2002). Gabriela, clavo y canela; crónica de una ciudad de

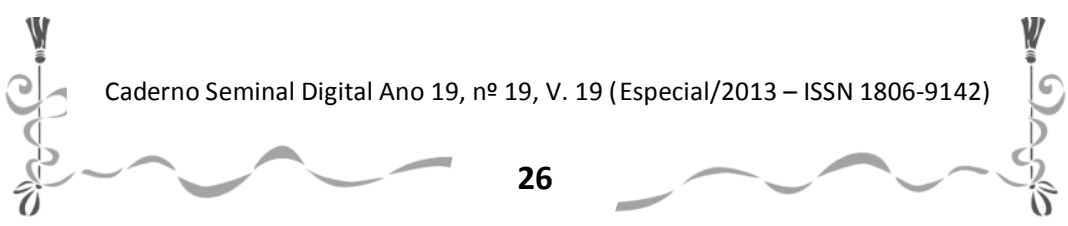


A

\section{Caderno Seminal Digital}

interior. Trad. Dante Hermo. Barcelona: El Aleph.

Carbonell, O. (1997). Traducir al otro. Toledo: Escuela de Traductores de Toledo.

Golden, S. (2003). Un modell teòric del procés de la interculturalitat: els estudis interculturals. Benvinguts! Identitat Nacional i Diversitat Cultural: El repte de la immigració als països catalans, Barcelona: Fundació Congrés de Cultura Catalana, p. 1-17.

Houaiss, A. \& Villar, M. S. (2001). Dicionário Houaiss da língua portuguesa. Rio de Janeiro: Objetiva.

Katan, D. (1996). The translator as cultural mediator. Programma Sociología Internazionale, Sezione Relazione Internazionali, Cuaderno n. 96-2, Gorizia: Istituto di Sociologia Internazionale.

Kristeva, J. (1994). Estrangeiros para nós mesmos. Rio de Janeiro: Rocco.

Martínez, L. M. (2001). Análisis descriptivo de la traducción de los culturemas árabe-español. Tesis doctoral, Universitat Autònoma de Barcelona en Bellaterra.

Newmark, P. (1988). Manual de traducción. Trad. C. V. Moya. Madrid: Akal.

Nida, E. A. (1945). Linguistics and ethnology in translation problems en Word 1. In: Rey, A. (org.). La Lexicologie. Vol. II. Paris: Klincksieck.

Peirce, C. S. (1931-1935). Collected papers, 8 vols. Cambridge: Harvard University Press.

Mendes, R. M. (2004). La traducción de las marcas culturales: la Bahía de Jorge Amado en español y catalán

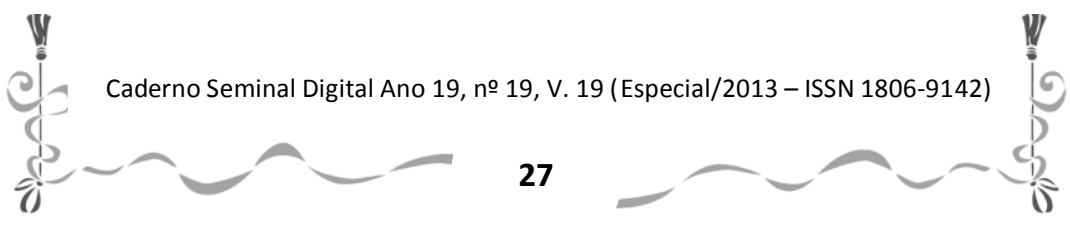


Caderno Seminal Digital

(trat

Digital

(trad. Laia Beltrán). Bellaterra: UAB.

Saussure, F. (2000). Curso de linguística general. Trad. Mauro Armiño. Madrid: Akal.

Todorov, T. (1993). A conquista da América; a questão do outro. São Paulo: Martins Fontes. 